\title{
Dieciocho apuntes sobre el dieciocho
}

\author{
Eduardo Rinesi
}

Politólogo e filósofo. Professor

Associado Regular da Universidad

Nacional de General Sarmiento,

Argentina, da qual foi reitor entre 2010 e 2014, onde coordena a Especialização em Filosofia Política. Autor de mais de dez livros sobre teoria social e política, dentre eles Politica y tragedia (2003), ¿Cómo te puedo decir? (2013), Filosolía

(y) politica de la Universidad (2015), Actores y soldados

Recebido em: 8 de maio de 2018 (2016) e Dieciocho (2018). 
PALABRAS CLAVE:

Universidad; Reforma; Libertad; Derechos.

KEYWORDS: University;

Reform; Freedom; Rights.
Universitaria de 1918, y a cincuenta del Ilamado "mayo francés", el texto examina los impactos de estos acontecimientos sobre nuestros modos actuales de pensar la cuestión universitaria. Se estudia la dimensión latinoamericana de la Reforma, sus antecedentes y sus legados, la relación entre la tradición reformista y los movimientos nacional-populares de este último siglo, y los modos en los que la filosofía política europea pensó la movilización de los estudiantes franceses en 1968. También se analizan las categorías de "libertad" y de "derecho" y su interés para el examen actual de la Universidad y su lugar.

One hundred years after the University Reform of 1918, and fifty years after the so-called "French May", this text examines the impact of these events on our current ways of thinking about the university. The text studies Latin American dimension of the Reform, its sources and its legacies, the relationship between the reformist tradition and the national-popular movements of this last century, and the ways in which the European political philosophy thought the mobilization of the French students in 1968. It also analyzes the categories of "freedom" and "right" and their importance for the present discussion about University. 
El 26 de mayo de 2003, la Facultad de Derecho de la Universidad de Buenos Aires fue escenario de un suceso extraordinario. El viejo Fidel Castro, que el día anterior había asistido a la asunción del presidente Néstor Kirchner, debía dar un discurso en la sala de actos. El lugar se colmó antes de lo imaginado y los asistentes empezaron a desbordarlo. Era imposible llevar adelante el acto donde se había previsto, y los organizadores decidieron que el viejo líder de la revolución cubana hablara al público en la escalinata del edificio, hacia la calle. Entonces, ante la multitud que lo escuchaba, Castro hizo algo notable: hizo de esa misma situación un tema de su propio discurso, que en media docena de frases consiguió construir una narrativa heroica sobre la propia circunstancia en la que hablaba, una pequeña épica que sin dificultad remitía, ante un público bien dispuesto hacia este guiño, a la épica mayor de la que su propia figura era inseparable, y que presentó como la épica de una "salida de sî" de la Universidad al espacio público de la calle, la ciudad, la política, la historia. Castro era un universitario, un viejo dirigente estudiantil de la tradición de Julio Mella, quien había escrito a fin de los años 20 que la Universidad debía servir a la sociedad en su batalla contra las oligarquías y el imperialismo. Lo inspiraban el nacionalismo de José Martí y los ecos de la reforma universitaria que había estallado en Córdoba en 1918, y que ya había impactado, también, en Perú y en México (Portantiero, 1978). Es ese bagaje el que inspira al Movimiento 26 de Julio, grupo de las clases medias universitarias cubanas desde el que Castro invitó a combatir la dictadura de Fulgencio Batista: a salir a la calle en busca del pueblo y por el bien del pueblo. 
Hugo Biagini (2012) ha propuesto pensar la Reforma de 1918 como la segunda gran aventura de las juventudes latinoamericanas. La primera había sido la emancipación política, a comienzos del siglo XIX, cuando también había resultado decisivo - dice - el peso de la Universidad: de los estudiantes que habían recibido en universidades como la de Chuquisaca las influencias de las más renovadoras lecturas europeas (ver también de Gori, 2012). El Manifiesto liminar de la Reforma retoma aquella herencia al señalar que si la rebeldía había estallado en Córdoba era porque allí "los tiranos se habían ensoberbecido y era necesario borrar para siempre el recuerdo de los contrarrevolucionarios de Mayo", y asume esa misma disposición latinoamericanista que Biagini encuentra en los revolucionarios de un siglo antes: se dirige "a los hombres libres de Sudamérica", asegura estar viviendo "una hora americana” y se cierra saludando "a los compañeros de la América toda". Y por cierto que el discurso reformista, que se ha considerado "el primer discurso pedagógico popular latinoamericano" (Puiggrós, 1993, 121), tuvo una fuerte incidencia en la vida pública de varios países de la región. Sobre todo del Perú, donde el movimiento, un poco como en la Argentina de Yrigoyen, encontró un contexto favorable, aunque ese marco auspicioso de fines de los ańos diez, signado por la centralidad de la figura del presidente Augusto Leguía, "maestro de la juventud”, se trastocaría poco después, con Leguía entregado a los grupos de poder más concentrados de su paísen medio de un clima de violenta represión del movimiento estudiantil y de las luchas obreras. En ese marco, el activo dirigente estudiantil Víctor Raúl Haya de la Torre es deportado a México. Ahí creará la Alianza Popular 
Revolucionaria Americana, que Portantiero considera el producto más legítimo de la reforma universitaria y el primer gran partido nacional-popular del continente. Quizás menos estridentemente que en Perú, la Reforma Universitaria de 1918 influyó también en Chile, Venezuela, México y Brasil.

Los grandes hechos históricos suelen nutrirse de un variado conjunto de estímulos no siempre congruentes y que componen articulaciones nunca exentas de todo tipo de tensiones. Y se prolongan en la forma de una serie de legados que tampoco tienen por qué resonar de una única manera en las sensibilidades posteriores. Más bien, esos sucesos son nudos complejos hechos de hebras que se enlazan de maneras nunca muy precisas, y lo que después recuperamos de ellos suele ser también el producto de nuestro propio ejercicio de tirar desde nuestro presente de alguna de esas hebras. La Reforma de 1918 tiene esas características, y por eso la discusión sobre su herencia es una discusión llena de interés y de problemas. Adriana Puiggrós (1993) observa que el movimiento reformista acercó su discurso al campo nacional y propuso una pedagogía para ese sujeto al que llamamos "pueblo", pero también que esa orientación convivió con otra, liberal, que siempre fue más fuerte y que se terminó imponiendo. Eso explica el largo malentendido entre los grupos que han tendido a reclamar para sí la herencia legítima de la Reforma y el gran movimiento de masas del siglo pasado en el país. Entre reformismo y peronismo, en efecto, hay una relación difícil, reforzada por una cantidad de representaciones mutuas que vuelven a esas dos tradiciones, por momentos, casi opuestas. Contra ese modo de 
pensarse las cosas, Julián Dércoli (2018) insiste en la doble reducción que representa la monopolización del legado de la Reforma por el "reformismo" y la identificación de la idea misma de universidad democrática con lo que surge de esa tradición, y sostiene que existe una línea de continuidad entre la Reforma y el peronismo y que la política universitaria del peronismo se basó en las críticas que la Reforma había planteado a la vieja universidad contra la que se había sublevado en su momento. La historia democrática de la universidad argentina se desplegó con el aporte de movimientos que no suelen pensarse como integrando la tradición heredera de la Reforma. En contrapartida, es fácil advertir la paradoja de que la fuerza política que se ha representado a sí misma, a lo largo de este siglo, como detentando el monopolio de los valores del reformismo universitario hoy integre el gobierno que más sistemáticamente ha combatido esos valores al menos desde 1983.

4.

Hay un nombre que se destaca sobre otros en la línea de puntos que es posible trazar uniendo la Reforma con la historia posterior del peronismo. Manuel Ugarte había promovido una transformación democrática de la Universidad desde comienzos de la década del 10, y es casi legendaria su "gira continental" hablando a las juventudes de las grandes ciudades de toda América Latina. En su prédica de esos años, en los que se va operando el deslizamiento de sus posiciones "del socialismo al nacionalismo democrático" (Galasso, 2012, 127), la "cuestión” universitaria es inseparable de la "cuestión" nacional y de la "cuestión" social, y todas ellas cargan una decidida entonación antimperialista. El 11 de abril de 1918, Ugarte es el 
orador principal en el Acto de Fundación de la Federación Universitaria Argentina. Gabriel del Mazo, que sería uno de los protagonistas centrales de la Reforma, lo recuerda con especial consideración, poniendo su apoyo al movimiento por encima del de Alfredo Palacios y del de José Ingenieros. Ugarte apostaba por la construcción de una gran patria sudamericana, de un nacionalismo de los oprimidos (González, 2017, 55) inspirado en los pensamientos de Bolívar y de Martísin abandonar nunca su vocación de izquierda. Es esa vocación la que lo lleva, a diferencia de Lugones, a rechazar el golpe nacionalista de Uriburu. Es esa vocación la que lo lleva, a diferencia de Vasconcelos, a plantear la idea de unidad continental en términos democráticos, y no espiritualistas. Así, el pensamiento de Ugarte anticipa los dilemas de la "izquierda nacional" argentina de la segunda mitad del siglo XX: de John William Cooke y de Jorge Abelardo Ramos. Ugarte fue embajador de Perón en México y en Cuba. Se distanció de Perón cuando entendió que su gobierno abandonaba el nacionalismo antimperialista que lo había entusiasmado. Murió en Niza en 1951.

5

El 28 de diciembre de 1959, un hijo de la universidad pública argentina recibía el título de Doctor Honoris Causa de la Universidad Central de las Villas, en Cuba. En el famoso discurso con el que acepta esa distinción, Ernesto "Che" Guevara aprovechó para exponer sus ideas sobre la función de la Universidad en esa "Cuba nueva" que daba recién sus primeros pasos. Reclamó que la Universidad "se pinte de negro, que se pinte de mulato, 
que se pinte de obrero y de campesino, que se pinte de pueblo, porque la Universidad no es el patrimonio de nadie y pertenece al pueblo", y ese pueblo está a las puertas de la Universidad, y la Universidad deberá abrirle esas puertas para que el pueblo entre a ella, se apropie de ella y la pinte con los colores que le parezca. ¿Cómo no oír en estas frases los ecos dela Reforma, de su condena a la Universidad como refugio de los mediocres, de su apuesta por un sujeto que se siente capaz de sacudirla desde sus cimientos? Pero Guevara no es Deodoro Roca, ni el discurso de Las Villas es el Manifiesto Liminar. Porque el sujeto en el que pensaban los reformistas no dejaba de ser un sujeto minoritario y relativamente tranquilizador. Oscar Terán (1999) ha indicado que la Reforma fue un movimiento juvenilista, no popular; de "renovación de las élites", no de crítica a las bases de una sociedad elitista. El sujeto del Manifiesto es la juventud; el del discurso del Che, el pueblo. Por supuesto, Guevara no se engańa: conoce las urgencias del corto plazo, sabe que la llegada del pueblo a la Universidad no es cosa de un día. Quiere por eso, dice, que se prepare la juventud estudiosa del país, para que cada uno pueda de inmediato tomar el puesto en el que la revolución lo necesite. Pero también quiere que sea todo el pueblo el que tenga derecho a la enseñanza, que no puede ser más el privilegio de los ricos. Por supuesto, no es que el pueblo no tenga un lugar en los grandes textos que produjo la Reforma, que lo hacen destinatario principal de los afanes de la juventud universitaria, que debe acercarse a él, extenderse hacia él. Pero esos textos nunca llegaron a hacer de ese pueblo el sujeto de lo que el Che llamó, en su discurso de 1959, un "derecho" a la Universidad. 
6.

Cuando uno se pone a hablar, se dice que "toma la palabra". "Toma la palabra el senador Tal”. Pero cuando el que habla es otro, que por ejemplo nos dice que piensa hacernos una visita o que nos va a regalar su último libro, decimos, a veces, "Te tomo la palabra”, y ahí "tomar la palabra” significa algo diferente: significa, no ya ponerse - uno - a hablar, sino agarrarse de la palabra del otro y anunciarle a ese otro que nos la tomamos muy en serio y que vamos a hacérsela cumplir. En un sentido importante, una parte decisiva de esa actividad propia de los hombres a la que damos el nombre de política se encierra entre estos dos sentidos de la expresión "tomar la palabra”, porque la política es tanto comprometer la propia palabra ante los otros como avisarles a esos otros que la palabra que ellos comprometen ante nosotros no nos es indiferente. Pero hay todavía un tercer sentido en que la expresión "tomar la palabra" puede utilizarse, y es un sentido que hereda la mitología asociada a un hecho fundamental de la vida política occidental moderna, que es la Revolución Francesa, cuyo relato es inseparablede la figura de una toma. De otra toma: la toma de la Bastilla. La Revolución Rusa, que se pensó sobre el telón de fondo de aquella otra, tuvo también su propia toma, que fue la de otro edificio: el Palacio de Inverno. Pues bien: son esas imágenes las que pone en juego Michel de Certeau en un libro sugerentemente titulado La toma de la palabra, que se refiere al movimiento de los estudiantes franceses de mayo de 1968, que marcó un hito en la historia del movimiento estudiantil y de las luchas juveniles del siglo XX, y que de Certeau nos invita a pensar también bajo la inspiración de la figura de una toma. No de la toma de un edificio, sino de la toma de la palabra: de 
la palabra en las calles y en las plazas y en las puertas de las facultades y de las fábricas. Claro que la palabra, después de tomada, puede ser recuperada, retomada, por sus antiguos señores, y la tesis que esboza de Certeau es que es justo eso lo que pasó en París pocos meses después de ese agitado mayo del 68. Es posible que de Certeau tenga razón, lo que no nos exime de la tarea de pensar qué fue lo que entre tanto ocurrió ahí, qué fue lo que se trastocó (y se trastocó sin duda de manera perdurable) en las calles, las plazas, las universidades y las fábricas parisinas durante esos meses tan intensos.

7.

La expresión que ya usamos cuando nos referimos a Augusto Leguía, "maestro de la juventud", se repite todo a lo largo del continente en esos mismos años 10 y 20 para aludir a personajes como José Vasconcelos, José Enrique Rodó, Alfredo Palacios, José Ingenieros, Rubén Darío. María Pia López (2010) destaca que el movimiento de impugnación de las sensibilidades heredadas de esos años lo fue también de búsqueda de nuevos liderazgos espirituales, y recupera los relatos de Conrado Nalé Roxlo, Julio Irazusta y José María Monner Sans sobre su asistencia informal a las clases de los grandes profesores de ese tiempo. Los jóvenes de esos años querían reformar el mundo, pero no se proponían hacerlo sin el auxilio de los nuevos maestros que se procuraban. Si rechazaban "el derecho divino del profesorado universitario" es porque no podía ser ésa la base de la autoridad pedagógica. El Manifiesto no reclama la abolición de esa "vinculación espiritual", sino el derecho de los jóvenes a elegir a sus maestros. ¿Tienen razón quienes han destacado la continuidad entre la reforma cordobesa de 1918 y el mayo 
francés de medio siglo más tarde? Sin duda. Pero no puede dejar de señalarse el modo diferente en que en uno y otro movimiento se despliega este asunto de la relación entre la juventud universitaria y la figura de los "maestros". Porque en París lo que entra en cuestión es exactamente esa figura: la del maestro. Incluso y sobre todo - como han destacado Federico Galende (2011) y Jésica Rojas (2018) - la del maestro de izquierda, sostenida sobre la idea de una distancia insalvable entre la ciencia verdadera y la ideología de quienes, presos de su propia confusión, no podrían nunca redimirse por sí mismos.

8.

Una de las más célebres imágenes que han llegado hasta nosotros de la Reforma de 1918 es la que muestra a un pequeño grupo de estudiantes alcanzando la cima del edificio de la Universidad y sosteniendo un mástil muy alto rematado, al final, por una bandera. Esa fotografía es muy famosa, y no hay duda de que lo es por el modo en que logra condensar una cantidad de sentidos que aparecen con singular fuerza en el espíritu y en la retórica del movimiento del que ha venido a convertirse en un emblema. Y en cuya copiosa discursividad son omnipresentes, en efecto, las imágenes de cimas y de cumbres y de cielos como ese que, en la foto, uno de los estudiantes parece estar - como se dice - "tocando con las manos". En la fotografía que estamos comentando, el sentido que domina es, en efecto, el de lo vertical. La posición de los cuerpos de los estudiantes empinados en la cumbre del edificio describe la forma de un triángulo que recuerda lo que Leopoldo Lugones (1960) había escrito siete años antes, en su delirante Historia de 
Sarmiento, sobre la figura, la morfología y el movimiento de las llamas y de las montañas, y más en general, toda una retórica sobre puntas y cumbres y cúspides en las que resuenan las influencias de Sorel, de Bergson, de Simmel, de Emerson y de Nietzsche. Es que es una y la misma la razón que le permite a Terán, como ya vimos, afirmar que la Reforma del 18 fue un movimiento de renovación de las élites, y no de cuestionamiento de la lógica desigualitaria de la sociedad que las producía, y la que hace que en la foto que rescata e inmortaliza la épica estudiantil de 1918 el sentido que domina el cuadro sea el de lo vertical, y que el triunfo de los estudiantes pueda representarse como una toma, no de la palabra, sino del cielo.

9.

El día del centenario del nacimiento de Herbert Marcuse, su discípulo Jürgen Habermas lo homenajeó recuperando su figura como la de un intelectual comprometido en los debates de su tiempo, como alguien que había puesto el gran legado de las investigaciones y de las reflexiones de los miembros de la "primera generación" de la gran "Escuela de Frankfurt" al servicio de la mejor comprensión de los dilemas de su propio momento histórico y de la discusión democrática en torno a esos dilemas. Yo leí ese artículo, recuerdo, en la Folha de S.Paulo, que acompañaba el texto con una hermosa fotografía que ilustraba un momento de una asamblea o una reunión en medio dela revuelta del movimiento estudiantil francés de 1968. En ella se veían a muy corta distancia, enfrentados y discutiendo acaloradamente, los rostros de un ya anciano Herbert Marcuse y de un joven con barba y melena à la John Lennon. Los dos rostros, en el primer plano de la foto, 
eran muy nítidos; el bullicio de la multitudinaria reunión se adivinaba en el fondo fuera de foco de la imagen. Los dos hombres se miraban fijamente y discutían con pasión, las dos bocas abiertas en sendos gritos simultáneos. Era una foto impresionante, y lo que aquí quiero señalar de ella es que el ostensible sentido que la animaba era el sentido de lo horizontal. Una línea horizontal, en efecto, unía los ojos de uno y los del otro; otra, paralela, la boca de uno y la del otro. Uno de los hombres era cincuenta años más viejo que el otro, pero no había en su actitud nada que nos hiciera pensar que supusiera que esa diferencia jugara de algún modo a su favor en la discusión que se estaba desplegando. El otro era medio siglo más joven que su interlocutor, pero no había en su gesto nada que nos indicara que la madurez del otro le producía ni desprecio ni veneración. Eran dos hombres adultos discutiendo. Que esa discusión fuera posible es quizás la lección de mayo de 1968.

10.

La historia de la reflexión filosófica sobre la Universidad acompańa como una sombra a la historia de la propia Universidad desde los escritos de René Descartes hasta los de Jacques Derrida, con un momento muy alto en El conflicto de las Facultades, de Immanuel Kant, donde pueden leerse dos cosas. Una, que el uso de la razón en las facultades que entonces se llamaban "superiores" (la de Derecho, la de Teología y la de Medicina) debía ser un uso privado. ¿Privado de qué? De libertad, porque el ejercicio de esa libertad podía hacer peligrar el orden público. La otra, que ese uso privado de la razón en esas tres facultades superiores debía compensarse con 
un uso plenamente público (es decir: ilimitado) de la razón en la Facultad de Filosofía, sin cuyo trabajo de examen de todo lo que la Universidad pensaba y enseńaba se corría el riesgo del dogmatismo o de la servidumbre intelectual. Ciento setenta años después, Habermas (1989) escribió un libro notable, Conocimiento e interés, que vuelve sobre el mismo tema en la perspectiva de lo que él llama emancipación. Habermas distingue allí tres tipos de conocimiento, cada uno de ellos asociado a un cierto tipo de interés: por un lado, el conocimiento nomológico, cuyo modelo es el de las ciencias naturales, asociadas a un interés técnico por la apropiación del mundo; por otro lado, el conocimiento hermenéutico, cuyo modelo es el de las ciencias sociales, asociadas a un interés práctico por la comunicación intersubjetiva; por último, el conocimiento re-flexivo, cuyo modelo es el psicoanálisis, asociado a un interés crítico por la emancipación. El libro de Habermas es de 1968, el mismo ańo en que Marcuse discutía con el estudiante que parecía John Lennon. Horizontalidad, pues, e introspección, o simplemente crítica: mirada re-flexiva del saber que examina sus propias condiciones, y salida al mundo de ese saber autoconsciente para intervenir en las grandes discusiones colectivas. Conocimiento e interés es el modo en el que Habermas participó en las barricadas de París.

Todo el Manifiesto está habitado por la palabra "libertad", que casi siempre hay que entender en el sentido más clásicamente liberal de unas libertades que deben defenderse de las fuerzas que pueden amenazarlas, como las corporaciones, el clero o el poder político estatal. Libertades 
"de", entonces, o "negativas" (Constant, 1988). De todos modos, a esta idea sobre la libertad vienen a sumarse también, en el propio Manifiesto, otras dos, que si han sido menos subrayadas a lo largo de la historia de la lectura de ese escrito es solo porque durante todo ese tiempo la perspectiva que dominó esa lectura fue largamente hegemonizada por el liberalismo de los grupos políticos y universitarios dominantes en nuestro país. Una es la idea de la libertad entendida como libertad "para", o positiva. No como protección frente a unos poderes externos que pueden amenazarnos, sino como posibilidad de realizar nuestros proyectos en el mundo, y de participar - de manera "deliberativa y activa", como solía decir en la Argentina José Nun (2000) inspirado en los trabajos de Carole Pateman - en los asuntos públicos. Esta es la idea que moviliza el Manifiesto cuando reclama "un gobierno democrático" integrado por los miembros de los distintos claustros. La otra es la idea de la libertad que empieza por entender que nadie puede ser libre en una sociedad que no lo es, y que podemos llamar, siguiendo una larga tradición, "republicana". Cuando se dice, en efecto, "Hombres de una República libre", está claro que lo "libre" no son los ciudadanos individuales, sino la república como cuerpo colectivo, común. O mejor: que solo hay libertad como cosa individual si hay también, como condición de ella, libertad como cosa pública, como res publica. Primero. Y segundo: que en este sentido la libertad no se nos aparece como opuesta al Estado, porque muchas veces es justo la intervención activa del Estado la que les permite a los individuos y a los pueblos ser más libres. 
Pero además de hablar sobre la cuestión de la libertad, el Manifiesto habla sobre el problema del derecho, o de los derechos. Palabra complicada, difícil, cuyo propio estatuto no suele ser sencillo precisar. Entre otras cosas porque, notémoslo, solemos decir que "tenemos derecho" a las cosas a las que, de hecho, no "tenemos" derecho: nadie que de hecho puede comer dos veces por día dice que tiene derecho a hacerlo, y eso nos hace preguntarnos a qué orden de la realidad corresponde lo que nombra esta palabra. Como sea: la palabra "derecho" aparece en el Manifiesto cuando sus autores afirman que el anacrónico régimen universitario que combaten "está fundado sobre una especie de derecho divino: el derecho divino del profesorado universitario", y se repite tres frases después cuando señalan que "el derecho a darse el gobierno propio radica principalmente en los estudiantes". La primera frase es una caracterización burlona de una realidad que se presenta como absurda; la segunda, una exigencia que quiere fundar un tiempo nuevo. La primera alude al derecho que se llama objetivo: de los derechos que existen y que organizan las posiciones de los sujetos en el mundo; la segunda, a los derechos que se llaman subjetivos: a los derechos que se postula que asisten (insistimos: que se postula que los asisten justo porque, de hecho, no lo hacen) a unos determinados sujetos, a los que por lo tanto deben reconocérseles si no se los quiere seguir agraviando. Los procesos de democratización de la vida pública de los países de nuestra región durante el último siglo pueden ser pensados como procesos de 
ampliación, profundización, universalización, de este tipo de derechos. Es decir, de realización de estos derechos. Porque los derechos, por definición, son universales o no son. O no son derechos. Lo cual es otro modo de decir que avanzar en el sentido de la democratización de una sociedad es avanzar en la comprensión de que no es posible que determinadas posibilidades sigan siendo prerrogativas de unos pocos, porque tienen que ser (porque es un escándalo que no sean: la idea de derecho es inseparable de la idea de escándalo) posibilidades ciertas y efectivas para todos.

La historia del debate político en América Latina entre el fin del último ciclo de dictaduras militares y los tres primeros lustros del siglo XXI es la historia del desplazamiento desde la idea de democracia hacia la idea de la democratización. En este marco, en el año 2008 tiene lugar en Cartagena de Indias un hecho fundamental en la historia de nuestros modos de pensar la Universidad: la reunión de la Conferencia Regional de Educación Superior del IESALC/UNESCO, cuya Declaración Final indica que la educación superior es un derecho humano universal. Nunca antes se había formulado una pretensión así. La Universidad, durante los cerca de mil años que tiene en la historia de la cultura de los países de Occidente, siempre se había pensado como lo que siempre había sido: una máquina de fabricar élites, y solo en el extraordinario contexto político que conoció nuestro continente unos ańos atrás pudo pensarse y postularse la idea de que debiera ser considerada un derecho universal. Es parte de los debates que tenemos por delante este año, 
en el que se desarrollará en Córdoba una nueva Conferencia Regional, si seremos capaces de que el documento final de esta reunión sostenga todavía, una década después y en un contexto muy distinto, aquel revolucionario principio de la Declaración de la CRES de diez años atrás.

Ahora: ¿qué quiere decir que la educación superior es un derecho humano?¿Qué agrega ese adjetivo, "humano", a la idea de derecho? Es claro que al usarlo queremos distinguir un específico conjunto de derechos que por la razón que sea nos parece que deben ser especialmente valorados. ¿Y cuáles son esos derechos? La respuesta que hemos dado a esta pregunta ha ido variando a lo largo del tiempo, y hoy, después de las experiencias políticas que signaron a nuestra región durante los quince primeros años de este siglo, tenemos sobre los derechos humanos una idea bastante más rica que la que teníamos antes. Breve: si durante las últimas décadas del siglo pasado el calificativo de "humanos" designaba, como "por la negativa", a aquellos derechos de cuya violación el Estado había sido (o eventualmente era, todavía) responsable, durante las primeras décadas de este esa designación sirve para identificar además, "por la positiva", a un conjunto de derechos que le corresponde al Estado garantizar, porque sólo él puede hacerlo. Designar el derecho a la educación superior como un derecho "humano" significa pues decir que el Estado tiene que estar ahí, con políticas activas, para garantizar la posibilidad efectiva y cierta de su ejercicio por parte de todo el mundo. 
Decir que la Universidad es un derecho humano es decir -ya lo indicamosque el Estado debe ocuparse de garantizarlo. En ese sentido, la expansión del sistema universitario ocurrida en nuestros países en las últimas décadas es una condición básica de posibilidad del ejercicio de ese derecho por parte de una enorme cantidad de ciudadanos a quienes de nada les serviría la indicación legal de que los asiste un derecho a la educación superior si, entre otras cosas, no tuvieran una universidad pública, gratuita y buena a un rato razonable de viaje de la casa. También hay que valorar las políticas de apoyo a la finalización de la escuela secundaria, al ingreso a la Universidad y al sostenimiento de los estudios en ella. Pero me gustaría subrayar que el compromiso con la idea de la Universidad como derecho tiene que animar también, más que lo que lo ha hecho hasta aquí, las prácticas y representaciones de los propios actores universitarios. Para empezar por nosotros, profesores, es necesario que nos tomemos muy en serio la idea de que cada joven sentado frente a nosotros cuando damos una clase no es alguien a quien le hacemos el favor de explicarle nada, sino el sujeto de un derecho que nosotros tenemos que garantizarle. Y que si ese joven no aprende no es porque sea portador de ninguna "carencia", sino porque nosotros no estamos a la altura de nuestra obligación. Decir que la Universidad es un derecho humano es decir que no podemos, nunca más, oír en las salas de profesores de nuestras universidades las quejas que todavía debemos oír sobre nuestros estudiantes. Que no son más deficitarios respecto a lo que "deberían ser" como estudiantes que lo que nosotros lo somos respecto a lo que "deberíamos ser" como profesores. Que llegan a nuestras universidades 
sabiendo lo que el sistema del que las universidades forman parte ha sido capaz de enseñarles hasta ese punto, y que llegan para ejercer allí un derecho que nosotros, trabajadores de ese sistema del que las universidades forman parte, debemos garantizarles. Y que no es solo el derecho a "entrar", sino también el derecho a permanecer, avanzar, aprender. Y a hacer todo eso en el más alto nivel. Es este un asunto fundamental, que colisiona con el sentido común elitista que anima la vida de nuestras instituciones desde hace unos diez siglos y que nunca fue seriamente revisado. Veámoslo un poco más de cerca.

16.

No se trata aquí de definir qué cosa es el bendito "nivel" de los estudios superiores ni de decir cómo debería medirse tal cosa: nuestra preocupación es mucho más general y, si pudiéramos decirlo así, previa. Lo que aquí quiero decir es que, si nos tomamos en serio la idea de que la Universidad es un derecho, no hay, no puede haber, tensión alguna entre "cantidad" y "calidad", entre "masividad" y "excelencia". Que no es verdad que haya que elegir entre tener una universidad, un sistema universitario o un sistema educativo bueno y tener una universidad, un sistema universitario o un sistema educativo para todos. Si pensamos la Universidad como un derecho, una universidad que expulsa o deja en el camino a la mayor parte de los que lo iniciaron y, al cabo de unos años, produce un puñado de graduados excelentes no es una universidad excelente: es una mala universidad. Si nos tomamos en serio la idea de la Universidad como un derecho, una universidad solo es buena si es buena para todos. Pero 
con la misma fuerza con la que escribimos esto queremos escribir también que si nos tomamos en serio la idea de la Universidad como un derecho, una universidad solo es para todos si es, para todos, buena. Si no, es un fraude, una mentira que viene a confirmar los prejuicios que debería combatir, y que son inaceptables. En efecto, es solo un prejuicio torpe, perezoso y reaccionario el que puede llevarnos a pensar que los más no pueden hacer, en el mismo nivel de calidad, lo mismo que los menos. Es ese prejuicio, que habita nuestras instituciones - ya lo dijimos - desde el inicio mismo de su historia, y que ni los estudiantes cordobeses de 1918 ni los franceses de medio siglo después se propusieron combatir, el que tenemos que poner en entredicho si nos tomamos en serio la absolutamente novedosa idea de que la Universidad es o puede o debe ser tenida como un derecho humano universal.

\section{7}

Pero además de ser un derecho individual de los ciudadanos, la Universidad es un derecho colectivo del pueblo. ¿Qué quiere decir esto? Primero, que el pueblo tiene derecho a que las universidades que sostiene formen para él, en el más alto nivel de calidad, los profesionales que ese pueblo necesita. ¿Que necesita para qué?: pues para realizarse, para desarrollarse (Zaffaroni, 2015), para ver garantizados otros derechos que también lo asisten. ¿Qué significa, por ejemplo, postular que el pueblo tiene un "derecho a la salud" si eso no incluye postular, entre otras cosas, que tiene derecho a tener los profesionales necesarios para que ese derecho no sea solo nominal? Claro que es muy difícil responder quién puede decir cuántos profesionales de este 
o aquel rubro "necesita" un pueblo. Pero aquí no importa. Porque aquí lo que interesa dejar establecido es apenas el principio general de que no puede ser solamente mirando a la garantía de los derechos individuales de los ciudadanos que las universidades organicen su oferta formativa. Segundo, que la Universidad es un derecho del pueblo significa que el pueblo debe poder aprovechar el resultado de los conocimientos que la Universidad produce, que no puede ser que después circulen apenas a través de los inaccesibles papers con los que jugamos el juego más bien banal de nuestros prestigios académicos: la Universidad debe aprender también, además, el mucho más exigente lenguaje con el que participar con eficacia en las grandes discusiones colectivas. Tercero, que la Universidad es un derecho del pueblo significa que el pueblo tiene derecho a ser algo más que un objeto de investigación, preocupación o auxilio por parte de las universidades. La Universidad, solemos decir, debe tener "las puertas abiertas". Esta figura se vuelve más potente si pensamos esas puertas no abiertas solamente hacia afuera, para dejarnos salir a nosotros, universitarios, a extender graciosamente nuestros saberes hacia el pueblo, sino también hacia adentro, de manera de dejar que sea el pueblo el que ingrese a la Universidad y la vivifique desde adentro.

Si la idea de la Universidad como derecho es, dijimos, tan sugerente como complicada, la retórica de la derecha hoy gobernante en la región es en cambio perfectamente simple. Sus voceros no usan nunca la palabra "derecho", porque no creen que esa palabra tenga ningún significado. Su 
discurso es constatativo: las cosas son así. Y entonces la palabra "derecho", que se instala en el hiato que se abre entre el plano del ser y el del deber ser y es hija del escándalo que nos produce la existencia de ese hiato, pierde sentido. O solo puede tener el que le da un "relato" necesariamente falsificador de las cosas, ingenuo en el mejor de los casos, mentiroso en el peor. La derecha es parmenídica: el ser es, el no ser no es. La pregunta del ingeniero Macri a propósito de la reciente expansión de nuestro sistema universitario, “¿Qué locura es ésta?”, expresa el pensamiento de quien sabe que, de hecho, la Universidad no es (nunca fue, hace mil ańos que no es) para todos, y puede poner una importante política de ampliación de derechos a la cuenta de la fantasía de un grupo de alucinados que creyó que el mundo podía ser distinto de lo que es. ¿Pero no se piensa parecido a eso cuando, dizque "por izquierda", se confunde la "seriedad" académica con la disposición seguidista, cómplice, a tomar aplicada nota de cómo funcionan las cosas en el mundo, a copiar tablas estadísticas, a repetir las constataciones que ya hizo hace cincuenta años Pierre Bourdieu (¡pero que Bourdieu hizo para que conociéramos la fuerza delo que tenemos que cambiar, no para que nos solazáramos en su expectación bobalicona y fascinada!), a seguir explicándonos que, por mucho que abramos universidad eso que escribamos en el texto de la ley que la Universidad es un derecho, a los hijos de los pobres les seguirá yendo peor que a los hijos de los ricos, y a completar esa sarta de tonterías con la invitación a que no engañemos más a los muchachos, a que no les sigamos diciendo que tienen los derechos que, de hecho, no "tienen", a que dejemos de una vez por todas los relatos? Es contra esa invitación que escribimos estas páginas. 


\section{REFERENCIAS BIBLIOGRÁFICAS}

Biagini, Hugo. La contracultura juvenil. De la emancipación a los indignados. Buenos Aires: Capital Intelectual, 2012.

Constant, Benjami. "De la libertad de los antiguos comparada con la de los modernos”. In: Del espiritu de la conquista. Madrid: Tecnos, 1988.

De Certau, Michel,. La toma de la palabra y otros escritos políticos. México: Universidad Iberoamerican, 1995.

De Gori, Esteban. La república patriota: Travesías de los imaginarios y de los lenguajes politicos en el pensamiento de Mariano Moreno. Buenos Aires: Eudeba, 2012.

Dércoli, Julián. "La Reforma Universitaria, el reformismo y las transformaciones universitarias del peronismo". In: Rinesi, Eduardo, Peluso, Natalia y Ríos, Leticia (comps.). Las libertades que faltan. Las dimensiones latinoamericanas de la Reforma Universitaria de 1918. Los Polvorines: UNGS, 2018, en prensa.

Derrida, Jacques. El lenguaje y las instituciones filosóficas. Barcelona: Paidós, 1995.

Galasso, Norberto. Manuel Ugarte y la unidad latinoamericana. Buenos Aires: Colihue, 2012.

Galende, Federico. Rancière. Una introducción. Buenos Aires: Quadrata y Biblioteca Nacional, 2011.

González, Horacio. Manuel Ugarte. Modernismo y latinoamericanismo. Los Polvorines: UNGS, 2017.

Habermas, Jürgen. Conocimiento e interés. Madrid: Taurus, 1989.

Kant, Immanuel. El conflicto de las facultades. Buenos Aires:Losada, 2004.

López, María Pia. Hacia la vida intensa. Una historia de la sensibilidad vitalista. Buenos Aires, Eudeba, 2010.

Lugones, Leopoldo. Historia de Sarmiento. Buenos Aires: Eudeba, 1960. 
Nun, José. Democracia. ¿Gobierno del pueblo o gobierno de los políticos?. Buenos Aires: FCE, 2000.

Portantiero, Juan Carlos. Estudiantes y política en América Latina. El proceso de la reforma universitaria (1918-1938). México: Siglo XXI, 1978.

Puiggrós, Adriana. La educación popular en América Latina. Buenos Aires: Miño y Dávila, 1993.

Rancière, Jacques. La lección de Althusser. Buenos Aires, Galerna, 1975.

Rojas, Jésica y Córdoba, Cintia. "Tomar la palabra, tomar la universidad, formar parte de la comunidad”. In: Rinesi, Eduardo, Peluso, Natalia y Ríos, Leticia (comps.). Las libertades que faltan. Las dimensiones latinoamericanas de la Reforma Universitaria de 1918. Los Polvorines: UNGS, 2018, en prensa.

Terán, Oscar. "La Reforma Universitaria en el clima de ideas de 'la nueva sensibilidad'”. In: Espacios, 24, 1999, 3-7.

Zaffaroni, Raúl. El derecho latinoamericano en la fase superior del colonialismo. Buenos Aires: Madres de Plaza de Mayo, 2015. 